\title{
Phytomedicinal importance of Saraca asoca (Ashoka): an exciting past, an emerging present and a promising future
}

\author{
Satpal Singh, T. H. Anantha Krishna, Subban Kamalraj, Gini C. Kuriakose, \\ Jinu Mathew Valayil and Chelliah Jayabaskaran*
}

Department of Biochemistry, Indian Institute of Science, Bengaluru 560 012, India

Since the dawn of civilization, natural resources have remained the mainstay of various remedial approaches of humans vis-à-vis a large number of illnesses. Saraca asoca (Roxb.) de Wilde (Saraca indica L.) belonging to the family Caesalpiniaceae has been regarded as a universal panacea in old Indian Ayurvedic texts and has especially been used to manage gynaecological complications and infections besides treating haemmorhagic dysentery, uterine pain, bacterial infections, skin problems, tumours, worm infestations, cardiac and circulatory problems. Almost all parts of the plant are considered pharmacologically valuable. Extensive folkloric practices and ethnobotanical applications of this plant have even lead to the availability of several commercial $S$. asoca formulations recommended for different indications though adulteration of these remains a pressing concern. Though a wealth of knowledge on this plant is available in both the classical and modern literature, extensive research on its phytomedicinal worth using state-of-the-art tools and methodologies is lacking. Recent reports on bioprospecting of $S$. asoca endophytic fungi for industrial bioproducts and useful pharmacologically relevant metabolites provide a silver lining to uncover single molecular bio-effectors from its endophytes. Here, we describe socio-ethnobotanical usage, present the current pharmacological status and discuss potential bottlenecks in harnessing the proclaimed phytomedicinal worth of this prescribed Ayurvedic medicinal plant. Finally, we also look into the possible future of the drug discovery and pharmaceutical R\&D efforts directed at exploring its pharma legacy.

Keywords: Drug discovery, herbal medicine, Saraca asoca, natural products, plant extracts.

FROM the dawn of civilization and throughout human history, the reliance of mankind on plants and other natural resources for everyday needs, including health benefits and cures for diseases is well documented ${ }^{1,2}$. Plants and plant-derived crude and semi-purified formulations have

\footnotetext{
*For correspondence. (e-mail: cjb@biochem.iisc.ernet.in)
}

remained the bedrock of human therapeutic systems since times immemorial, so much so that even today majority of the clinically successful compounds for treatment of various illnesses, including cancer, microbial infections, etc. remain either direct plant products or derivatives thereof ${ }^{2}$. The drugs and drug leads derived from natural sources, including plants are believed to have evolved over enormous evolutionary time periods, thereby imparting them high biological potency which results from many factors, including their complex structures and extraordinary biochemical specificities ${ }^{2}$.

The pivotal role played by natural products in drug discovery and development could be gauged by the fact that these products (together with their synthetic or semisynthetic cousins) accounted for about $50 \%$ of the $\sim 900$ new chemical entities clinically introduced between 1981 and 2002 (ref. 2). Well known clinically used compounds such as anticancer drugs Taxol ${ }^{3-6}$, camptothecin ${ }^{5}$ and podophyllotoxin ${ }^{6}$, vinca alkaloids-vincristine and vinblastine $^{6}$, antimalarials such as artemisinin ${ }^{5,6}$, immunosuppressive drug cyclosporine, etc. are prominent examples of natural resources-derived drugs. About a quarter of modern clinical drugs used in USA alone are derived from plants and an estimated $80 \%$ of world population relies primarily on herbal medicines for primary healthcare needs ${ }^{7,8}$. Secondary metabolites such as alkaloids, terpenoids, polyketides, steroids, flavonoids, phenolics, glycosides, etc. have remained the major contributors in addressing the traditional and modern pharma needs of mankind. Not only are they used directly as therapeutic entities, but also as raw materials for developing novel structural derivatives based on clinically validated scaffolds. Rising concerns about the unwarranted side effects of many allopathic drugs coupled with drug resistance are pushing the re-entry of herbal drugs into the clinical R\&D laboratories. In fact, in the past decade the international trade in herbal medicines alone was estimated at nearly USD 60 billion and is estimated to reach several hundred billions US dollars in near future $^{2,3}$. The growing number of publications and patents on this subject similarly point to a surge in global interest in this field ${ }^{1}$. Therefore, there is an urgent need to 
systematically research the well-established medicinal plants using state-of-the-art tools and methodologies to derive the maximum pharma benefit from them.

India is known for a rich tradition of ethnobotanical medicine-based remedial practices primarily involving medicinal plants and their products. The country accounts for sizeable biodiversity on the planet ${ }^{3}$. Various traditional treatment systems such as Ayurveda, Unani, Siddha, etc. have been extensively practised by locals since ancient times. Close to 25,000 effective plant-based drug formulations have been reported in traditional Indian folk medicine ${ }^{3}$. It is estimated that currently several thousand manufacturing units are involved in the production of natural health products and traditional plant-based formulations ${ }^{3}$. Moreover, about two-thirds of the Indian population is reported to rely directly or indirectly on the herbal and other natural products for health needs ${ }^{3}$. In a fastdeveloping society like ours, it is hoped that with such a vast natural resource- and traditional knowledge-base, we can rightfully aspire to become global leaders in supplying safe, effective and economical health products to the international market.

This article details the traditional ethnobotanical and pharmaceutical utility of $S$. asoca and highlights the current pharmacological status of this well-known medicinal plant. We also present some aspects of modern plant-based drug development paradigms which might advance its medicinal utility. Finally, we discuss the lacunae in the current $S$. asoca-based pharmacological applications and attempt a sneak peek into the possible future strategies to harness its well-reported pharmacological potential.

\section{Saraca asoca (Ashoka or Ashokbriksh)}

Ashok or Ashoka (which is a Sanskrit term meaning one 'without sorrow or grief') also called 'Ashokbriksh' and botanically known as Saraca asoca (Roxb.) W. J. de Wilde or Saraca indica L. is among the most ancient medicinal plants known in India. It belongs to the family Caesalpiniaceae. Known by many local names in different languages, this plant has been regarded as a universal panacea in old Indian Ayurvedic texts and has been reported to be thus used since ancient times.

Reaching a final height of 7-10 m, this evergreen and deciduous tree displays a profuse branching pattern with paripinnate leaves and orange to scarlet fragrant flowers arranged in dense lateral corymbs (Figure 1). The geographical distribution of Saraca is mainly in Asia and some parts of North America. The tree is found mainly throughout India, especially in West Bengal, Assam, Odisha, Tamil Nadu, Karnataka, Kerala, Andhra Pradesh, Meghalaya and Maharashtra ${ }^{9}$. It is also widely distributed across the Western Ghats (both South and Central), the Sahyadri region and throughout the Himalayas. S. asoca is also found in countries such as Pakistan, Sri Lanka, Bangladesh as well as Burma and in Malay where it grows at an altitude of $\sim 750 \mathrm{~m}$ (ref. 9-11). Saraca declinata also known as Red Saraca is present in Florida (USA), Burma and Sri Lanka ${ }^{12}$. Almost all plant parts such as bark, flowers, leaves and seeds are considered therapeutically valuable due to the presence of secondary metabolites such as alkaloids, terpenoids, flavonoids, steroids, glycosides, anthraquinones, phenolics, tannins, saponins and other phytochemicals (vide infra Phytochemistry) which are generally considered the biologically active ingredients in most natural products and herbal formulations ${ }^{13-61}$.

Owing to a large number of $S$. asoca herbal formulations consumed locally through ethnobotancical or commercial products, the domestic demand for Ashoka bark in India was reported to be more than 5000 metric tonnes during 1999-2000 span and about 15,000 metric tonnes during 2007-2011 (ref. 13). Interestingly, there are several formulations/products based on this plant made available commercially by major herbal/Ayurvedic pharmaceutical companies (Table 1).

\section{Socio-cultural practices, ethnobotanical uses and classical treatises on biological/pharmacological properties of $S$. asoca}

The Ashoka tree occupies a privileged place in many Indian folk and socio-cultural traditions. It has been revered in the Hindu tradition ${ }^{14}$. The legendary Indian text, Ramayana has a mention of the Ashoka tree. Married women in India are known to eat Ashoka flower buds as a ritual to invoke deities for child protection as well as and gynaecological problems ${ }^{14}$. Natives in India wear root pieces of Ashoka as herbal rosary for mental tranquility. Women in many tribes of Chhattisgarh, India consume decoction of Ashoka bark in cow's milk and sugar for three days once in three months

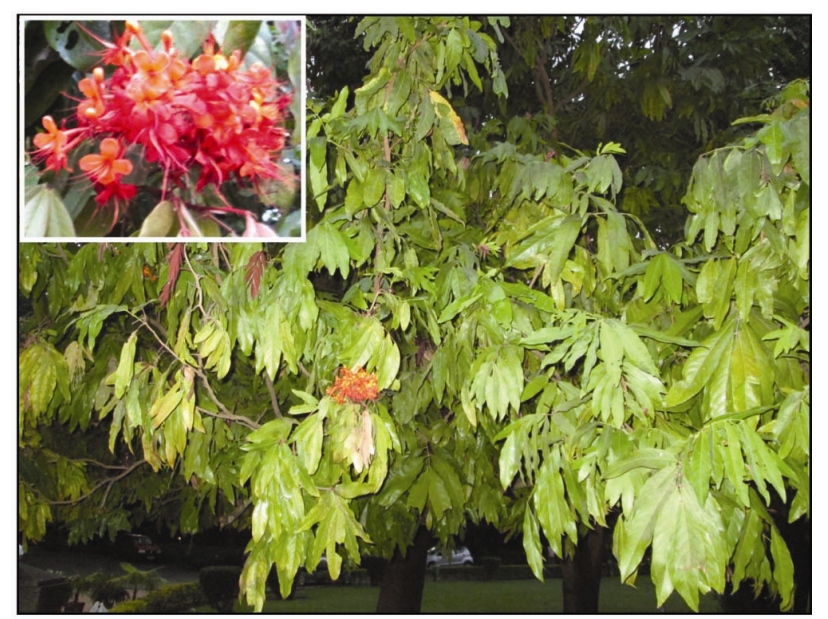

Figure 1. Saraca asoca plant and its flowers (inset). 
REVIEW ARTICLE

Table 1. Various commercially sold Ashoka-based herbal drugs/formulations*

\begin{tabular}{|c|c|c|c|}
\hline Trade name & Form & Indications recommended for & Company \\
\hline Evecare $^{a}$ & $\mathrm{~S}$ & Menstrual disorders & Himalaya \\
\hline Menosan $^{a}$ & $\mathrm{~T}$ & Menopause-related indications & Himalaya \\
\hline Ovoutoline $^{\mathrm{a}}$ & S\&T & Menorrhagia, dysmenorrhea, irregular menstruation, postmenopausal syndrome & Zandu \\
\hline Restone $^{\mathrm{a}}$ & $\mathrm{T}$ & Premenstrual tension, menopausal syndrome, genitourinary diseases & Maharishi Ayurveda \\
\hline Menorex $^{b}$ & $\mathrm{C}$ & Menorrhagia, dysmenorrhea, irregular menstruation & Arya Vaidya Pharmacy \\
\hline Femiplex $^{\mathrm{a}}$ & $\mathrm{C}$ & Leucorrhoea & Charak \\
\hline Shvet $^{\mathrm{a}}$ & $\mathrm{C}$ & Leucorrhoea, menorrhagia, dysfunctional uterine bleeding & $\begin{array}{l}\text { Shree Dhanvantari } \\
\text { Herbals }\end{array}$ \\
\hline Pradarsudha $^{a}$ & $\mathrm{~S}$ & Leucorrhoea, menorrhagia & Patanjali Ayurved \\
\hline Femohills $^{\mathrm{a}}$ & $\mathrm{C}$ & Leucorrhoea, menorrhagia, dysmenorrhea, lower back pain & Herbalhills \\
\hline Menocramp $^{a}$ & $\mathrm{~T}$ & Spasmodic and lower back pain, stress and mood swings & Solumiks \\
\hline Ashotone $^{\mathrm{a}}$ & $\mathrm{T}$ & Excessive bleeding, stress & Solumiks \\
\hline Asok Churna ${ }^{\mathrm{b}}$ & $\mathrm{P}$ & Leucorrhoea, dysmenorrhea, gynecological disorders & Hidco \\
\hline M2-Tone Forte ${ }^{\mathrm{a}}$ & $\mathrm{S}$ & Excessive bleeding, menstrual flow issues & Charak \\
\hline M2-Tone ${ }^{\mathrm{a}}$ & $\mathrm{T}$ & Irregular menses, gynaecological disorders & Charak \\
\hline Masturin $^{\mathrm{a}}$ & $\mathrm{S}$ & Irregular menses, leucorrhoea, dysmenorrheal, uterine inflammation & Hamdard \\
\hline Ashokrista $^{a}$ & $\mathrm{~S}$ & $\begin{array}{l}\text { Leucorrhoea, dysmenorrhea, menorrhagia, dysfunctional uterine bleeding, } \\
\text { gynecological disorders }\end{array}$ & Several \\
\hline
\end{tabular}

*Source: Internet. This is not a comprehensive list. ${ }^{\mathrm{a}}$ Ashoka + other herbs, ${ }^{\mathrm{b}}$ Ashoka only; ${ }^{\mathrm{c}}$ Ashoka + ayurvedic formulation; S, Syrup; T, Tablets; C, Capsules and P, Powder.

to avoid gynaecological problems as well as diabetes ${ }^{14-15,21}$. Women suffering from menorrhagia drink a decoction on an empty stomach in the morning, which is prepared from the bark of Ashoka in water in combination with other herbs such as Terminalia chebula and Coriandrum sati$v_{u m}{ }^{14,62}$. In leucorrhoea, the decoction of Ashoka bark in water and milk after evaporation of water is consumed by women. Ksheerapaka preparation of Ashoka bark is used to stop abnormal vaginal discharges ${ }^{14}$. The paste of Ashoka bark is known to relieve uterine pain. In India, Sri Lanka, Bangaldesh and Pakistan, Ashoka bark is used by womenfolk in treating menorrhagia, menstrual and uterine disorders ${ }^{10,14,62}$.

$S$. asoca plant has remained one of the oldest known medicinal plants in Indian texts dating back to thousands of years. Ayurvedic texts from the medieval period till recent times clearly highlight the various beneficial uses of $S$. asoca. Classical Ayurvedic treatise of Charaka Samhita (1000 BC) describes the effectiveness of $S$. asoca as an analgesic and astringent as well as in skin diseases, including leprosy ${ }^{16}$. The treatise of Susruta (500 BC) describes its uses in disorders of the womb in particular, as well as in fever, neurological disorders, snake bites, disease of the eye and wounds ${ }^{16}$. Vaghbatta (6th century $\mathrm{AD})$ described the use of its seeds in cough ${ }^{16}$. The Ayurvedic text book Dhanvantari Nighantu (9th century AD) recorded the use of Ashoka as a cooling agent, aromatic and cardiac tonic with curing effects for wounds, ulcers, haemorrhoids and bone fractures ${ }^{16}$. In Chakradatta, a text of the 11th century, bark of Ashoka is prescribed for severe bleeding. It also mentions ingestion of seeds in the case of urine flow obstruction due to kidney stones ${ }^{16}$. The 12th century work Gadanigraha of Sodhala noted prescription of Ashoka bark to stop menorrhagia ${ }^{16}$. In $R a j$ Nighantu, an Ayurvedic text book of 14th century, Ashoka had been cited as a heart tonic and in the treatment of tumours and abdominal pain ${ }^{16}$. Similarly, 15th century AD Ayurvedic book Kayadeva Nighantu describes the uses of Ashoka bark and flowers in menorrhagia, bleeding piles, dysentery and to prevent abortion ${ }^{16}$. Bhavaprakasa, a famous Ayurvedic practitioner of the 16th century $\mathrm{AD}$ detailed its various applications such as in haemorrhagic disorders, worm infestations, oedema, etc ${ }^{16}$. Powdered bark of Ashoka with honey is mentioned for treating uterine bleeding in the 1676 text Yoga Ratnakara ${ }^{16}$. The 18th century Ayurvedic treatise Bhaisajya Ratnavali described two Ashoka preparations - Asokaghrita and Asokarista useful for treating haemorrhages, anorexia, oedema and fever by the former, and backache, uterus pain and anaemia by the latter ${ }^{16,62}$. The 19 th century AD text Saligram Nighantu cited the use of Ashoka to improve skin complexion as well as in treatment of abdominal pain, piles, abdominal complications, burning sensation, tumours, etc. ${ }^{16}$. The 1966 Ayurvedic text Osadhi Nighantu describes the use of Ashoka in the treatment of wounds, tumours, poisoning, diarrhoea, worm infestations, burning sensation, excessive menstrual bleeding and abdomen swelling ${ }^{16}$. The Unani system of medicine through the works of Hakeem Rajali Khan and Hakeem Azam Khan recorded Ashoka uses in anorexia, dermatitis, indigestion, animal bite and as a hair tonic. Bark is described to treat excessive salivation, flowers as a cardiac and brain tonic, while fruits are mentioned as contraceptive in nature ${ }^{16}$ 


\section{Biological and pharmacological properties of S. asoca: contemporary studies}

The old Ayurvedic texts combined with numerous ethnobotanical uses of this plant have inspired several research groups in India and elsewhere to systematically investigate its beneficial claims and test any novel pharmaceutical properties that it may possess.

Following section reviews the modern, literature-based reports on the biological and pharmacological properties of $S$. asoca.

\section{Antimennorhagic, oxytocic and uterine tonic}

The use of $S$. asoca dried bark, root and flowers to manage uterine abnormalities, menorrhagia (excessive menstrual bleeding), ammenorhea, painful periods, endometrosis and disorders of the menstrual cycle is well known in India $^{10,14,17-20,22-25,62}$. The root decoction of $S$. asoca is also consumed after delivery for enhanced lochial discharge ${ }^{14}$. Experiments have revealed the ability of bark aqueous extract to stimulate and relax the intestinal muscle, prolong uterine contractions and also as a uterine sedative $^{14,21}$. The uterine tonic application of the bark has been attributed to its effect on the endometrium and ovaries as an estrogenic stimulant $\mathrm{t}^{21,63}$. The ethanolic extract of the bark have been shown to be effective on the gravid uteri and the estrogen primed uteri ${ }^{14}$. A phenolic glycoside $\mathrm{P} 2$ isolated from $S$. indica has been shown to produce oxytocic activity both in vitro and in vivo on the animal uteri and in vitro on human myometrial tubes ${ }^{64}$.

\section{Antibacterial}

Numerous literature reports establish the antibacterial properties of methanolic, ethnolic, acetone and aqueous extracts of bark, dried flower buds and leaves of $S$. aso$\mathrm{ca}^{26-39,61}$. These have been tested against many pathogenic bacteria such as Bacillus subtilis, Escherichia coli, Salmonella typhosa, S. typhimurium, S. typhii, S. viballerup, S. enteritis, Staphylococcus aureus, Bacillus cereus, Klebsiella pneumonia, K. aerogenes, Shigella boydis, S. sonnei, S. flexneri, S. dyserteriae, Pseudomonas aeruginosa, P. vulgaris, Vibro cholerae, Proteus vulgaris, etc. As such this plant is a seemingly valuable resource to find single molecular antibiotics in the future against the backdrop of rising resistance of several human pathogenic bacteria to the known major antibiotics.

\section{Antifungal}

Traditionally fungal infections have been attributed to compromised immune response of an individual and not posing a very serious danger to the population at large; however, there have been increasing incidences of fungal disease outbreaks in the past. Finding new antifungal agents is therefore a priority of the clinical microbiology community. The antifungal activity of methanolic and hot aqueous extracts of $S$. asoca leaves, flowers and bark against Alternaria alternata, Colletotrichum gloeosporioides, Drechlera specifera, Alternaria cajani, Helminthosporium sp., Bipolaris sp., Curvularia lunata Aspergillus flavus, A. fumigates and Fusarium sp. have been reportedly shown by various groups ${ }^{31,61,65}$. These could be subjected to further detailed investigations for uncovering the bio-active principles.

\section{Anticancer}

Natural products have provided some of the most effective anticancer leads in the past, several already being into successful commercial production ${ }^{3-6}$. Ethnobotanical studies of $S$. asoca have revealed its flavonoid fraction (from flowers) to prevent two-stage skin carcinogenesis and preferentially act against Dalton's lymphoma ascites and Sarcoma-180 tumour cells, while being non-toxic to normal lymhpocytes ${ }^{40,66}$. The ethanolic extract of $S$. indica was shown to inhibit breast cancer ${ }^{67}$. Recently, the lectin 'saracin' isolated from the seed integument has been reported to induce apoptosis in human $\mathrm{T}$ lymphocytes in an in vitro assay ${ }^{68}$.

\section{Anti-inflammatory, antiarthritic and cardioprotective effect}

Chronic arthritis and cardiovascular diseases are generally attributed to the inflammatory response mediated by proinflammatory cytokines. The ethanolic and methanolic extracts of the leaf, bark and root of $S$. asoca have been shown to exhibit anti-inflammatory potential by significantly inhibiting the binding of various transcription factors such as NF- $\kappa \mathrm{B}$, AP-1, GATA-1, etc. to their target DNA sequences, thereby lowering the levels of proinflammatory cytokines ${ }^{11}$. S. asoca extract has also been shown to reduce the levels of pro-inflammatory cytokines IL-1 and TNF- $\alpha^{40}$. Several reports describe the antiarthritic potential of $S$. asoca using the model system of Carageenan-induced paw oedema and also brine shrimp assay ${ }^{14,21,33,41,69}$. Furthermore, $S$. asoca plant extracts have been shown to reduce the level of liver and lysosomal enzymes, serum collagen and restoring of normal histological architecture of joints, thereby reducing rheumatoid arthritis in rats ${ }^{43}$. The ethanolic extract of $S$. indica has been reported as anti-inflammatory and also shown to protect cardiac tissue from infiltration of inflammatory cells $^{70,71}$. S. asoca extracts are also known for their hemopurificatory effects ${ }^{14}$.

\section{Antiulcer}

The aqueous suspension extract of $S$. indica flowers, dried flower buds, bark and seeds were shown to curtail ulcers in albino rats ${ }^{21,33,41,43-45}$. The anti-ulcer effect of the aqueous extract of $S$. indica flowers was demonstrated 
in albino rats by employing two models, namely pyloric ligation (which increases the acid content in the stomach) and aspirin-induced gastric ulcer. In both these experiments, the volume of gastric juice produced and the acidity and ulcer index were shown to be reduced remarkably compared to the control rats, when treated with the aqueous extract of $S$. indica ${ }^{45,71}$. The antiulcerogenic effect of these extracts could probably be attributed to the presence of saponins, triterpenes, tannins, catechin, sterols, phenolic glycosides and flavonoids ${ }^{44,45}$. The molecules responsible for ulcer reduction are thought to act either by inhibition of basal gastric secretion and/or stimulation of mucus secretion and/or endogenous gastric mucosal secretions which are triggered by prostaglandin $\mathrm{E}_{2}$ and $\mathrm{I}_{2}$ synthesis, and/or antioxidant activity of the flavonoids present in the aqueous extract of $S$. indica which counter the reactive oxidants present in the gastrointestinal lumen ${ }^{21,33,44}$.

\section{Antioxidant, antidiabetic and hypolipidemic}

A number of reports have described the presence of various antioxidant compounds such as ascorbic acid, catechin, flavonoids, lignin glycosides, $\beta$-sitosterol and its glucosidic form, polyphenolics such as gallic acid in petroleum ether, chloroform and methanol extracts of $S$. asoca leaf, bark and flower $^{43,46-55,67}$. The flavonoid fraction of $S$. asoca flowers and leaves has been shown to inhibit $\alpha$-glucosidase and $\alpha$ amylase enzymes linked to type-2 diabetes and also prevent LDL (low density lipoprotein) oxidation ${ }^{46,53,55}$. These reports have also reported $S$. asoca extracts lower lipid and cholesterol content and reduce the elevated glucose levels in a dose-dependent manner in streptozotocin-induced diabetic albino rats and mice ${ }^{46,55}$. They have also been reported to reduce the diabetes-induced renal oxidative stress. Application of this plant extract has also been shown to improve pancreatic, renal and hepatic profiles as well as the overall health in diabetic mice ${ }^{55,72,73}$.

\section{Analgesic}

There is a wealth of information on the analgesic effect of $S$. asoca in traditional medicine texts which has been demonstrated by experiments that used methanolic, petroleum ether, chloroform and aqueous extracts of the bark and leaves ${ }^{33,42,56}$. The analgesic property of $S$. indica has been attributed to its ability to inhibit sensory nerve stimulation (early phase), which was experimentally validated using three different methods, namely tail immersion method, tail flick method (which uses an analgesiometer) and formalin induced pain method ${ }^{41,43}$. Since inflammatory responses contribute to the development of pain, the antiinflammatory activity described above might explain the analgesic effect of $S$. asoca during the late phase of pain development ${ }^{11,33,42,70}$. Thus, it is assumed that $S$. asoca extracts typically relieve pain by acting on both the central and peripheral nervous systems ${ }^{56}$.

\section{Anti-nephrolithiatic}

$S$. asoca root has been reported to be used in conditions of urinary passage obstruction due to kidney stones and is known for its potency to dissolve oxalic acid stones present in the kidney ${ }^{14,62,74}$.

\section{Central nervous system depressant and brain tonic}

Depression and anxiety are increasingly regarded as health risks. Central nervous system (CNS) depressant activity of $S$. indica leaves has been revealed by the methanolic extracts which showed maximum CNS depressant activity in albino mice ${ }^{14,75}$. The same extracts were reported to reduce the onset of sleep. They also prolonged the duration of sleep induced by pentobarbitone. Additionally, they resulted in the decreased locomotor activity in mice ${ }^{75}$. The mechanism of the depressant activity can be associated with the activation of $\gamma$-aminobutyric acid (GABA) receptors in the CNS by glycosides, flavonoids, saponins and tannins present in the plant extract, which culminates in anxiolysis, muscle relaxation and sedation ${ }^{75,76}$.

\section{Dermatoprotective}

The root, bark and seed extracts of $S$. asoca find several uses in the treatment of skin complications such as eczema, psoriasis, acne, dermatitis, herpes-kushta/ visarpa, pruritis, scabies, tinea pedis and skin cancer ${ }^{40,57}$. The flower extracts of $S$. asoca which contains flavonoids, has been shown to reduce skin tumours induced by 7,12 -dimethyl benzanthracene ${ }^{40}$. It is also known to rejuvenate skin complexion, induce quick healing of skin injuries, reduce freckles and external inflammations of the skin $^{14}$. Seed extracts have been reported to be effective against dermatophytic fungi ${ }^{14}$.

\section{Larvicidal}

Combating the menace of insects such as mosquitoes is the major priority in the battle against communicable diseases such as malaria, dengue, filariasis, etc. The petroleum ether and chloroform extracts of the bark, leaves and flowers of $S$. indica have been shown to significantly reduce the population of the mosquito Culex quinquefasciatus ${ }^{21,32}$, thereby controlling the breeding of insect vectors.

\section{Anti-helminthic}

Presence of parasitic worms in the human body leads to malnutrition, weakness and susceptibility to bacterial and viral infections. Methanolic extracts of $S$. asoca leaves have been reported to paralyze and kill the adult Indian earthworm, Pheritima posthuma which resembles the human round-worm parasite p $^{33,77}$. 


\section{Antimutagenic and genoprotective effect}

Mutagenesis by any source can cause cancer and other debilitating diseases. S. asoca has been known as a good source of antioxidants which can reduce mutagenesis. Recently, S. asoca bark extract has been reported to prevent mutagenesis in Salmonella strains $^{58}$. This extract had also been shown to protect Swiss albino mice against cyclophosphamide-induced genotoxicity ${ }^{59}$. Interestingly, a lignin glycoside 'saracoside' isolated from $S$. asoca stem bark has been reported as a potent inhibitor of DNA topoisomerase IB, an important enzyme involved in many processes where DNA unwinding is essential such as replication, transcription, recombination, etc. ${ }^{58,59}$.

\section{Other medicinal uses}

Dried root of $S$. asoca has been reported to be useful in paralysis, haemiplegia and visceral numbness showing its effect through the parasympathetic and autonomous nervous systems ${ }^{14}$. The extracts of $S$. asoca seeds and dried flowers have shown properties of being an osteoid tissue promoter such as in treatment of rickets, delayed bone consolidation and calcium deficiency ${ }^{14,57,78}$. Antipyretic action of methanolic extracts of S. ascoa leaves has been recently reported ${ }^{79,80}$. Similarly, many other biological/ pharmacological actions of its various extracts have been reported such as an antidote in snake bite, an antileucorrhea agent, a contraceptive, and in the treatment of dysentery, worm infestations and stomach pain ${ }^{57}$.

\section{Phytochemistry}

It is well known that the various biological activities of herbal medicines result primarily from the their secondary metabolites which are generally classified as alkaloids, terpenoids, steroids, flavonoids, phenolics, tannins, saponins, glycosides, quinones, volatile organic compounds, etc. based on different criteria such as chemical nature, metabolic origin, precursor molecules of primary metabolism, presence of nitrogen, etc. Scientific evaluation of herbal formulations or plant-derived drugs helps in addressing the toxicity and other effects related to their use/abuse. This primarily includes systematic separation of raw/crude formulations into individual biomolecules or their defining classes, and subsequently test and validate their pharmacological worth in an appropriate experimental system. Discovery of new drug-like molecules/leads could be another offshoot of such an approach.

Several publications on the phytochemical analysis of S. asoca extracts from different plant organs have reported the presence of most of the above-mentioned metabolite classes (Tables 2 and 3). The most important and widely used part of the Ashoka plant is its bark, which is usually harvested from about a decade-old tree. Flowers are another important ingredient in many Ashoka herbal formula- tions. Various types of chemicals and biomolcules reported from different organs of Ashoka are as follows:

\section{Bark}

Bark of $S$. asoca is the most important organ vis-à-vis its medicinal value. It is known to contain flavonoids, tannins, steroids, volatile oil, glycosides, steroidal glycosides such as $\beta$-sitosterol glucoside ${ }^{14,21,48,50,72}$, reducing sugars, and many compounds of potassium, sodium, calcium, aluminum, strontium, calcium, iron, magnesium and phosphate $e^{14,21,43,50,60}$. Powdered bark also carries cellular species such as tracheids, stone, parenchyma, sieve tubes and other cells ${ }^{14}$. Lignin glycosides such as lyoniside, nudiposide, 5-methoxy-9- $\beta$-xylopyranosyl, isolariciresinol and schizandriside; flavonoids such as catechin, epicatechin, epiafzelechin- $(4 \beta \rightarrow 8)$-epicatechin, procyanidin $\mathrm{B} 2$, deoxyprocyanidin B, leukocyanidins and leucopelargo$\operatorname{nidin}^{61,81,82}$; and leucopelargonidin glucoside ${ }^{83}$ have been reported from $S$. asoca bark $^{14,21,48,50,61,81,82}$. Antioxidants such as polyphenolics, gallic acid and ellagic acid have also been described from $S$. asoca bark ${ }^{14,21,38,43,47-49,83}$.

\section{Leaves}

After the bark, leaves of $S$. asoca have remained the next best investigated plant tissue from the metabolic profile standpoint. They have been reported to contain alkaloids, steroids, flavonoids, tannins, saponins, terpenoids, polyphenolics, glycosides and many carbohydrates ${ }^{38,43,46,84-86}$. The antioxidant activity of the leaf extracts has been described to be due to the presence of polyphenolics such as gallic acid and ellagic acid ${ }^{38}$. Flavonoids such as quercetin, $\beta$-sitoterol, ceryl alcohol, and glucosides such as quercetin-3-O- $\alpha$-rhamnoside and kaemferol-3-O- $\alpha$-Lrhamnoside have been reported from $S$. soaca leaves $^{14,21,33,38,49,72,81,83,84}$.

\section{Flowers}

The flowers of $S$. asoca have been shown to contain tannins, flavonoids, saracasin, saracadin, waxy substances, carbohydrates, proteins and steroids ${ }^{43}$. They are especially known for the presence of many fatty acids such as oleic, palmitic, stearic, linolenic and linoleic acids; glucosides such as quercetin-3-O-P-D-glucoside, apigenin-7-O-p-Dglucoside, pelargonidin-3,5-diglucoside and cyanidine3,5-diglucoside; steroids such as $p$ - and $y$-sitosterols; flavonoids such as quercetin, leucocyanidin, and polyphenolics such as gallic acid and ellagic acid ${ }^{14,21,38,84}$.

\section{Seeds}

Seeds of $S$. asoca have been reported to contain various fatty acids such as oleic, linoleic, palmitic and stearic 
REVIEW ARTICLE

Table 2. List of various bioactive compounds reported from different organs of S. asoca

\begin{tabular}{|c|c|c|c|c|}
\hline Bioactive compound & Class of compound & Plant organ & Biological function & Reference \\
\hline Acetyl salicylic acid & Phenolic acid & Seed & Analgesic & 84 \\
\hline Gallic acid & Phenolic acid & Bark, flowers, leaves & $\begin{array}{l}\text { Hypolipidemic, antioxidant, } \\
\text { antidiabetic }\end{array}$ & $\begin{array}{l}14,21,38,43 \\
47-49,67,83\end{array}$ \\
\hline Ellagic acid & Phenolic acid & & Antioxidant & 38,83 \\
\hline Quercetin & Phenolic acid & & Antioxidant & $14,38,83-84$ \\
\hline Leucocyanidin & Flavonol & Seed, pod, bark & Anti-inflammatory & $81-82,84$ \\
\hline Leucopelargonidin & Flavonol & Bark, leaves & Anti-inflammatory & $61,81-82$ \\
\hline Benzene-1,2-diol & Catechin & Seed, pod, bark & Anti-inflammatory, antimicrobial & $61,81-82,109$ \\
\hline Epicatechin & Flavonol & Seed, pod, bark & $\begin{array}{l}\text { Anti-inflammatory, antioxidant, } \\
\text { antimicrobial }\end{array}$ & $50,61,81$ \\
\hline $3^{\prime}, 5$-Dimethoxy epicatechin & Flavonol & Bark & Anti-inflammatory, antimicrobial & 82 \\
\hline Procyanidin B2 & Flavonol & Bark & Antioxidant & 50 \\
\hline Gallocatechin & Flavonol & Bark & Anti-inflammatory & 82 \\
\hline Epigallocatechin & Flavonol & Bark & Anti-inflammatory, antimicrobial & 61,82 \\
\hline Haematoxylin & Flavonol & Bark & Diagnostic purpose (staining of tissues) & 84,109 \\
\hline Quercetin-3-O-P-D-glucoside & Flavonol glycoside & Flowers & Antioxidant & 14 \\
\hline Pelargonidin-3,5-diglucoside & Flavonol glycoside & Flowers & Antidiabetic, anti-cataract & 83 \\
\hline Cyanidin-3,5-diglucoside & Flavonol glycoside & Flowers & Antidiabetic & 83 \\
\hline $\begin{array}{l}\text { 3'-Deoxyepicatechin-3-O- } \beta \text {-D- } \\
\text { glucopyranoside }\end{array}$ & Flavonol glycoside & Bark & Anti-inflammatory & 82 \\
\hline $\begin{array}{l}\text { 3'-Deoxycatechin-3-O- } \alpha-\mathrm{L}- \\
\text { rhamnopyranoside }\end{array}$ & Flavonol glycoside & Bark & Anti-inflammatory & 82 \\
\hline Lyoniside & Lignan glycoside & Bark, leaves, flowers & Antioxidant & $48,50,61,82$ \\
\hline Nudiposide & Lignan glycoside & Bark & Antioxidant & $48,50,61$ \\
\hline $\begin{array}{l}\text { 5-Methoxy-9- } \beta \text {-D-xylopyranosyl- } \\
\text { isolariciresinol }\end{array}$ & Lignan glycoside & Bark & Antioxidant & 48,50 \\
\hline Icariside $\mathrm{E}_{3}$ & Lignan glycoside & Bark & Antioxidant & 48,50 \\
\hline Schizandriside & Lignan glycoside & Bark & Antioxidant & 48,50 \\
\hline$\beta$-Sitosterol & Sterol & Bark, leaves, stem & $\begin{array}{l}\text { Hypolipidemic, antioxidant, } \\
\text { antidiabetic }\end{array}$ & $\begin{array}{l}14,21,49,72 \\
\quad 81,83\end{array}$ \\
\hline$\beta$-Sitosterol glucoside & Steroidal glycoside & Bark, leaves & $\begin{array}{l}\text { Hypolipidemic, antioxidant, } \\
\text { antidiabetic }\end{array}$ & $\begin{array}{c}14,21,48 \\
50,72\end{array}$ \\
\hline Stearic acid & Fatty acid & Seed, pod & & 81 \\
\hline Oleic acid & Fatty acid & Seed, pod & Anti-inflammatory, cardioprotective & 81 \\
\hline Linoleic acid & Fatty acid & Seed, pod & Anti-inflammatory, cardioprotective & 81 \\
\hline
\end{tabular}

Table 3. Major classes of bioactive compounds reported from various $S$. asoca organs using various extracting solvents

\begin{tabular}{|c|c|c|c|c|}
\hline Class of compounds & Plant organ & Extraction solvent & Biological function & Reference \\
\hline Phenolic acids & Bark, flowers, leaves & Ethyl acetate & $\begin{array}{l}\text { Hypolipidemic, anticancer, } \\
\text { antioxidant, antidiabetic }\end{array}$ & $\begin{array}{l}14,21,38,43,47-49, \\
67,83-84\end{array}$ \\
\hline Flavonols & Seed, pod, bark, leaves & $\begin{array}{l}\text { Hexane, benzene, } \\
\text { chloroform, methanol, } \\
\text { water, hot water }\end{array}$ & $\begin{array}{l}\text { Anti-inflammatory, } \\
\text { antioxidant, antimicrobial }\end{array}$ & $50,61,81-82,109$ \\
\hline Flavonol glycosides & Bark, flowers & Ethanol, methanol, water & $\begin{array}{l}\text { Anti-inflammatory, antioxidant, } \\
\text { antidiabetic }\end{array}$ & $14,82-83$ \\
\hline Lignan glycosides & Bark, leaves, flowers & Methanol & Antioxidant & 50 \\
\hline Steroidal glycosides & Bark & Methanol & Antioxidant & $14,21,48,50,72$ \\
\hline Steroids & Leaves, stem & $\begin{array}{l}\text { Hexane, chloroform, methanol, } \\
\text { water, hot water }\end{array}$ & $\begin{array}{l}\text { Hypolipidemic, antioxidant, } \\
\text { antidiabetic }\end{array}$ & $14,21,49,72,81,83$ \\
\hline Alkaloids & Leaves & $\begin{array}{l}\text { Chloroform, ethanol, } \\
\text { methanol, water }\end{array}$ & Antioxidant & 43,46 \\
\hline Terpenoids & Leaves & Methanol & Antioxidant & 86 \\
\hline Fatty acids & Leaves, stem & Hexane, chloroform & Anti-inflammatory, cardioprotective & 81 \\
\hline Tannins & Bark & Acetone & Antioxidant & 84 \\
\hline
\end{tabular}


acids; sterols such as catechol and epicatechol; and a flavonoid, leucocyanidin ${ }^{14,21}$. Saracin, a lectin from $S$. asoca seeds has been reported as an inducer of apoptosis or even mitogenic in human T-lymphocutes ${ }^{68,84}$. Phenols, flavonoids, tannins, saponins, carbohydrates, glycosides and salicylates have been demonstrated in the acetone extracts of $S$. asoca seeds ${ }^{84}$.

\section{Fruits (pods)}

Fruits have been previously reported for the presence of various fatty acids such as oleic, linoleic, palmitic and stearic acids; sterols like catechol and epicatechol, and a flavonoid, leucocyanidin ${ }^{14,21}$.

\section{Roots}

There are no significant reports on the phytochemical analysis of $S$. asoca roots, though they have some reported ethnobotanical uses.

It is noteworthy that despite these reports on the phytochemical constituents of $S$. asoca organs, modern highend analytical tools, techniques and platforms for metabolite identification, analysis and validation - cornerstone of advanced drug discovery paradigms these days, however have not been explored extensively in $S$. asoca-based drug discovery and development approaches ${ }^{38,43,61,72,73,87}$. However, revigorated and more directed efforts of the scientific community and central bodies aimed at preserving and reviving the natural heath systems could become a much needed catalyst in furthering these studies.

\section{Endophytes of $S$. asoca: a potential new dimension to expand its herbal legacy}

Endophytes i.e. microorganisms (e.g. fungi, bacteria, etc.) asymptomatically residing inside the internal tissues of the plant hosts are known to symbiotically benefit the hosts ${ }^{88}$. These endophytes are typically isolated for pharmaceutical bioprospecting purposes from the well-known medicinal plants in ethnobotanical literature, as well as from plants growing in unique and challenging ecological habitats. Some of these endophytes are generally believed to have acquired the biosynthetic capability for various compounds which the host is known for. Anticancer drugs such as taxol $^{4}$, podophyllotoxin, camptothecin, vinca alkaloids such as vincristine and vinblastine are prominent examples ${ }^{89}$.

The well-known medicinal value of $S$. asoca would make this plant an ideal candidate for screening of its endophytes for pharmaceutically relevant compounds, including those originally ascribed to its herbal formulations. This, in principle, would call for identifying single chemical entities from $S$. asoca extracts that could be held responsible for the biological effects of its extracts though herbal formulations are known to exert their bio- logical effects due to combination(s) of many different compounds. A large body of literature reports on the medicinal value of many endophytes, especially endophytic fungi isolated from medicinally important plants provide the necessary push to venture into this arena ${ }^{90-94}$. So far, however, only a limited number of reports describe biomolecules of pharmaceutical or commercial significance from the endophytic fungi isolated from $S$. asoca ${ }^{94-99}$. These include an endophytic Acremonium sp. producing industrially relevant enzymes, an amylase ${ }^{95}$ (with wide uses in food, paper, pharmaceutical, textile, sugar and textiles industries) and a protease ${ }^{94}$, as well as the production of an antioxidant and anticancer steroidal saponin named cholestanol glucoside from an endophytic fungus Lasiodiplodia theobromae ${ }^{96-99}$. Reporting isolation of 37 endophytic fungal species belonging to 22 different genera, including Lasiodiplodia, Camarosporium, Pestalotiopsis and Fusarium, the same group reported significant in vitro cytotoxicity of 18 fungal extracts against three human cancer cell lines - HeLa, HepG2 and PC $3{ }^{99}$. Further, classical apoptosis-based in vitro anticancer activity of Pestalotiopsis sp. 6 has been reported by them ${ }^{99}$. Thus, in the scenario where endophytes of this plant prove to be of significant pharmaceutical potential with novel lead molecules or mimicking the bioactivities of the host plant, the modern industrial fermentation capabilities could be exploited, in principle, to harness their pharma worth, though a number of hurdles warrant concerted biotechnological efforts to realize that goal ${ }^{3,100}$.

\section{Lacunae in harnessing the high pharmaceutical potential of $S$. asoca}

Though the medicinal value of $S$. asoca is quite evident from the classical descriptions on its use in Ayurveda, Unani and Sidha systems as well as from several modern reports including those of the recent past, there remain many limitations in the proper pharmaceutical exploitation of this valuable plant. One of these lacunae relates to the lack of studies on proper scientific standardization and quality control of preparation of Ashoka formulations. This would seem especially evident from the reports on the adulteration of this plant material with noneffective plants. The main adulterants in bark are Polyalthia longifolia, Afanamexis polystakis and Sicalpinea pulchirena ${ }^{14,62,101,102}$. Therefore, identification of the right plant material by various modern tools such as spectroscopy, spectrometery, metabolomics, DNA barcodingbased techniques, etc. would prove valuable in ensuring a uniform and safe starting material of high quality. Also, it is well known that the plant age, climatic conditions and various biotic and abiotic pressures as well as time of sampling, etc. exert multiple biological effects on plant physiology, including metabolite production ${ }^{103-105}$ and at present, there is severe paucity of such studies on $S$. asoca. 
This calls for undertaking such investigations on Ashoka plant to help identify proper parameters for its cultivation, sample collection and process technologies to ensure maximum drug standardization leading to optimal clinical efficacy of its formulations/products.

The herbal ingredients used in $S$. asoca-based therapies require rigorous qualitative and quantitative standardization before therapeutic formulations are prepared as bacterial, viral, fungal and heavy metal contamination might remain a part of the crude formulations. Given that like other herbal products Ashoka formulations are a mixture of many compounds, it remains unknown as to which components, if at all, plays more significant role(s) in the biological effect(s) known from $S$. asoca extracts/formulations. Systematic identification of such molecular effectors and/or their combinations might prove useful in quicker designing of defined and superior Ashoka formulations. Though the bark extracts are known to act on the endometrium of the uterus, the mechanism of its action and its active principle(s) remain largely unknown ${ }^{28}$. Better scientific understanding of the same could generate information which might be useful to bring better and more refined molecular therapies to manage uterine diseases and related uses in other ailments, for example, muscular indications. Also, at present there remains inadequate research on the chemistry and molecular biology-based studies on physiology, metabolism and pharmacology of this plant using standard methodologies. For example, there is no information available on the biosynthetic origin of any pharmacologically significant compound reported from this plant.

\section{Future prospects in $S$. asoca-based drug discovery and pharmaceutical $R \& D$}

Societies like India with a wealth of traditional knowledge- and resource-base in health and fitness therapies would benefit greatly, both locally and globally, by integration of herbal-based health products in treatment regimens, especially as they are considered relatively harmless. In fact, because of Ayurveda and other alternative systems of medicine India has already become well known globally for many of these products ${ }^{6}$. Though the ethnopharmacological and traditional uses of $S$. asoca are well known, the key to bringing better, safer, more effective and standardized pharma products/formulations from this plant lies in conducting thorough and rigorous evidence-based modern experimental studies with well-defined and robust process parameters from sample collection till product finish. Stringent quality control practices in drug formulations and adulteration testing by reliable and emerging tools and techniques should be prioritized to augment the commercial attractiveness of Ashoka herbal products.

Ashoka cell-culture systems have not been established, which can become a fertile ground for investigating various aspects of the bioactive metabolite production by this plant using already established tools and methodologies. As the plant takes many years to reach maturity, the tissue culture techniques such as callus and suspension cultures could be explored to assess the production of useful secondary metabolites by them. It would be interesting to study the genetic signatures of biosynthetic pathways connected with certain known secondary metabolites from this plant, as such an approach might lead to engineering the Ashoka plants for specific metabolite profile and could encourage studies correlating the specific metabolites to defined biological effects. So far, chloroplast matK gene investigation and PCR-based identification of $S$. asoca-specific microsatellite markers remain the only molecular biology-related reports from S. asoca ${ }^{106,107}$. Systematic investigations of various Ashoka extracts by modern technology such as spectroscopy, spectrometery and various 'omics-approaches such as metabolomics', proteomics-based techniques are the need of the hour to tap its much acclaimed pharmacological potential. Uniform and safe raw materials combined with quick, efficient, robust and streamlined process engineering and protocols for preparation of Ashoka herbal products/formulations need to be investigated to ensure quality, efficiency, reproducibility and reliability of the final products.

Herbal formulations hold special promise for metabolic and degenerative diseases such as Alzheimer's, Parkinson and diabetes owing to their multifactorial causation. In this backdrop, the multi-component herbal formulations such as those from $S$. asoca might provide the elusive intervention since they would probably involve multiple biochemical targets simultaneously. Also, as the traditional use of certain plants has paved the course towards the discovery of several molecular therapeutics such as anticancer terpenoids such as $\mathrm{Taxol}^{3-6}$, camptothecin ${ }^{5}$, podophyllotoxin ${ }^{6}$; vinca alkaloids - vincristine and vinblastine ${ }^{6}$; and antimalarial, artemisinin ${ }^{5,6,108}$, the rationale for isolating useful bioactive principles from a well-known plant such as $S$. asoca appears highly promising - an area probably awaiting rich findings. Finally, pharmaceutical bioprospecting of $S$. asoca-associated endophytes could provide a new dimension to expand the pharma worth of this natural pharmacy.

\section{Conclusions}

$S$. asoca remains well known as a universal panacea in classical Indian texts with usefulness in treating many different gynaecological disorders apart from its many uses as uterotonic, anticancer, antibacterial, anti-helminthic, antiulcer, antioxidant, refrigerant, hypolipidemic, hypoglycaemic, anti-inflammatory, analgesic, febrifuge and skin infection curative agent along with many other health benefits. There are extensive uses of this plant in Ayurvedic, Unani and Siddha systems of alternative medicine. The plant however, has not been subjected to extensive modern scientific investigations, including 
spectroscopy, spectrometry, metabolomics and molecular and physio-chemical-based research paradigms vis-à-vis its known pharmacological value. Rising concerns on the side effects of many allopathic medicines coupled to the recent trend in the popularity of herbal and natural therapies is reviving the adoption of these treatment options even in the more developed nations. Therefore, purpose-oriented, rapid and clear scientific standardization for evaluation of the proper raw material, robust process design and quality control are required to develop more effective and safer therapeutic natural products from this important medicinal plant. Ashoka cell-culture systems could be exploited to study various aspects of its metabolite production such as molecular controls and environmental factors. Being a well-known source of novel and host plant-associated bioactive secondary metabolites, endophytes of $S$. asoca should be screened for pharmaceutically relevant metabolites which could prove valuable in extending its pharma worth.

1. Raskin, I. et al., Plants and human health in the twenty-first century. Trends Biotechnol., 2002, 12, 522-531.

2. Koehn, F. E. and Carter, G. T., The evolving role of natural products in drug discovery. Nature Rev. Drug Discov., 2005, 4, 206-220.

3. Kusari, S., Singh, S. and Jayabaskaran, C., Rethinking production of Taxol ${ }^{\circledR}$ (paclitaxel) using endophyte biotechnology. Trends Biotechnol., 2014, 32, 304-311.

4. Chakravarthi, B. V. S. K., Das, P., Surendranath, K., Karande, A. A and Jayabaskaran, C., Production of paclitaxel by Fusarium solani isolated from Taxus celebica. J. Biosci., 2008, 33, 259-267.

5. Oberlies, N. H. and Kroll, D. J., Camptothecin and taxol: historic achievements in natural products research. J. Nat. Prod., 2004, 67, 129-135

6. Patwardhan, B., Vaidya, A. D. B. and Chorghade, M., Ayurveda and natural products drug discovery. Curr. Sci., 86, 789-799.

7. Pandey, M., Rastogi, S. and Rawat, A., Indian herbal drug for general healthcare: an overview. Internet J. Altern. Med., 2007, 6.

8. Kamboj, V. P., Herbal medicine. Curr. Sci., 2000, 78, 35-39.

9. Murthy, S. M., Mamatha, B. and Shivananda, T. N., Saraca asoca - an endangered plant. Biomed., 2008, 3, 224-228.

10. Mollik, M. A. H., Hossan, M. S., Paul, A. K., Taufiq-Ur-Rahman, Jahan, R. and Rahmatullah, M., A comparative analysis of medicinal plants used by folk medicinal healers in three districts of Bangladesh and inquiry as to mode of selection of medicinal plants. Ethnobotany Res. Appl., 2010, 8, 195-218.

11. Saha, J., Mitra, T., Gupta, K. and Mukherjee, S., Phytoconstituents and HPTLC analysis in Saraca asoca (roxb.) Wilde. Int. J. Pharm. Pharm. Sci., 2012, 4, 96-99.

12. De Wilde, W. J. J. O., Saraca tubiflora, a new species from westcentral Sumatra (Caesalpinioideae). Blumea, 1985, 30, 425-428.

13. Beena, C. and Radhakrishnan, V. V., Quality assessment evaluation of the market samples of important ayurvedic drug Asoka bark. Ann. Phytomed., 2012, 1, 95-98.

14. Pradhan, P., Joseph, L., Gupta, V., Chulet, R., Arya, H., Verma, R. and Bajpai, A., Saraca asoca (Ashoka): a review. J. Chem. Pharm. Res., 2009, 1, 62-71.

15. Shukla, R., Chakravarty, M. and Gautam, M. P., Indigenous medicine used for treatment of gynaecological disorders by tribal of Chhattisgarh. Indian J. Med. Plant Res., 2008, 2, 356-360.

16. Biswas, T. K. and Debnath, P., Asoka (Saraca indica Linn) - a cultural and scientific evaluation. Indian J. Hist. Sci., 1972, 7, 99-114.
17. Middelkoop, T. B. and Labadie, R. P., Int. J. Crude Drug Rec., 1986, 24, 41-44.

18. Bhandary, M. J., Chandrasekhar, K. R. and Kaveriappa, K. M., Medical ethnobotany of the Siddis of Uttara Kannada District, Karnataka, India. J. Ethnopharmacol., 1995, 47, 149-158.

19. Kumar, Y., Haridasan, K. and Rao, R. R., Ethnobotanical notes on certain medicinal plants among some Garo people around Balphakram Sanctuary in Meghalaya. Bull. Bot. Surv. India, 1980, 22, 161-165.

20. Middelkoop, T. B. and Labadie, R. P., The action of Saraca asoca Roxb. de Wilde bark on the PGH2 synthetase enzyme complex of the sheep vesicular gland. Z. Naturforsch. C, 1985, 40, 523-526.

21. Mishra, A., Kumar, A., Rajbhar, N. and Kumar, A., Phytochemical and pharmacological importance of Saraca indica. Int. J. Pharm. Chem. Sci., 2013, 2, 1009-1013.

22. Saha, J. C., Savini, E. C. and Kasinathan, S., Ecbolic properties of Indian medicinal plants, part I. Indian J. Med. Res., 1961, 49, $130-151$.

23. Karnick, C. R., Acta Phytother., 1970, 17, 181.

24. Khan, M. A., Khan, T. and Ahmad, Z., Barks used as source of medicine in Madhya Pradesh, India. Fitoterapia, 1994, 65, 444446.

25. John, D., One hundred useful raw drugs of the Kani tribes of Trivandrum Forest Division, Kerala, India. Int. J. Crude Drug Res., 1984, 22(1), 17-39.

26. Pal, S. C., Maiti, A. P., Chatterjee, B. P. and Nandy, A., Antibacterial activity of flowers and flower buds of Saraca indica Linn. Indian J. Med. Rec., 1985, 82, 188-189.

27. Jain, S. R. and Sharma, S. N., Hypoglycaemic drugs of Indian indigenous origin. Planta Med., 1967, 15, 439-442.

28. Singh, A., Singh, S., Sarma, B. K., Singh, U. P., Srivastava, R. and Singh, K. P., Internet J. Altern. Med., 2009, 6, 1-20.

29. Rajan, S., Johnson, J. and Selvichristy, J., Antibacterial activity and preliminary screening of the extracts of the bark of Saraca asoca. J. Sci. Trans. Environ., 2008, 1, 149-151.

30. Annapurna, J., Bhalerao, U. T. and Iyengar, D. S., Antimicrobial activity of Saraca asoca leaves. Fitoterapia, 1999, 70, 80-82.

31. Seetharam, N., Sujeeth, H., Jyothishwaran, G., Barad, A., Sharanabasappa, G. and Shabana, P., Antibacterial activity of Saraca asoca bark. Indian J. Plant Sci., 2003, 65, 658-659.

32. Mathew, N., Anitha, M. G., Bala, T. S. L., Sivakumar, S. M., Narmadha, R. and Kalyanasundaram, M., Larvicidal activity of Saraca indica, Nyctanthes arbor-tristis, and Clitoria ternatea extracts against three mosquito vector species. Parasitol. Res., 2009, 104, 1017-1025.

33. Preeti, B., Bharti, A., Sharma, A. and Vishwabhan, S., A review on Saraca indica plant. Int. Res. J. Pharm., 2012, 3, 80-84.

34. Sarojini, N., Manjari, S. A. and Chandrakanti, C., Correlation between phytochemical screening and some biological activity using plant extracts. Int. J. Res. Ayurveda Pharm., 2011, 4, 13431348

35. Pal, S. C., Maiti, A. P., Chatterjee, B. P. and Nandy, A., Antibacterial activity of flowers and flower buds of Saraca indica. Ind. J. Med. Res., 1985, 82, 188-189.

36. Sainath, R. S., Prathiba, J. and Malathi, R., Antimicrobial activity of the stem bark of Saraca indica. Eur. Rev. Med. Pharm. Sci., 2009, 13, 371-374.

37. Nayak, S., Sahoo, A. M., Chakraborti, C. K. and Haque, M. N., Antibacterial activity study of Saraca indica leaves. Int. J. Pharm. Res. Dev., 2011, 3, 160-163.

38. Saha, J., Mukherjee, S., Gupta, K. and Gupta, B., Highperformance thin-layer chromatographic analysis of antioxidants present in different parts of Saraca asoca (Roxb.) de Wilde. J. Pharm. Res., 2013, 1-6.

39. Gomashe, A. V., Gulhane, P. A., Junghare, M. P. and Dhakate, N. A., Antimicrobial activity of Indian medicinal plants: Moringa 
oleifera and Saraca indica. Int. J. Curr. Microbiol. Appl. Sci., 2014, 3, 161-169.

40. Cibin, T. R., Devi, D. G. and Abraham, A., Chemoprevention of two-stage skin cancer in vivo by Saraca asoca. Integr. Cancer. Ther., 2012, 11, 279-286.

41. Preethi, F. and Krishnakumar, K., Anti-inflammatory activity of the barks of Saraca indica Linn. Pharmacology Online, 2011, 2, 657-662.

42. Saravanan, S., Babu, N. P., Pandikumar, P. and Ignacimuthu, S., Therapeutic effect of Saraca asoca (Roxb.) Wilde on lysosomal enzymes and collagen metabolism in adjuvant induced arthritis. Inflammopharmacol., 2011, 19, 317-325.

43. Saha, J., Mitra, T., Gupta, K. and Mukherjee, S., Phytoconstituents and HPTLC analysis in Saraca asoca (roxb.) Wilde. Int. J. Pharm. Pharm. Sci., 2012, 4, 96-99.

44. Lakshmi, K. N. V. C., Madhuri, M., Anwar, S., Ali, L., Bhimavarapu, P. and Shaik, A., Evaluation of antiulcerogenic activity of various extracts of Saraca indica bark on aspirin induced gastric ulcers in albino rats. Int. J. Res. Pharm. Chem., 2013, 3, 753-758.

45. Ahmed, C. Y., A study on the antiarthritic and antiulcer activities of Saraca indica Bark in rats and mice. Thesis, Department of Pharmacology, V. L. College of Pharmacy, Raichur, Karnataka, India. Abstr., 2011, page xiv. Discussion; pp. 147-148.

46. Jain, A., Jasmine, Sharma, S. and Saini, V., Hypolipidemic, hypoglycemic and antioxidant potential of Saraca asoca ethnolic leaves extract in streptozotocin induced-experimental diabetes. Int. J. Pharm. Pharm. Sciences, 2013, 5, 302-305.

47. Samee, W. and Vorarat, S., Simultaneous determination of gallic acid, catechin, rutin, ellagic acid and quercetin in flower extracts of Michelia alba, Caesalpinia pulcherrima and Nelumbo nucifera by HPLC. Thai Pharm. Health Sci. J., 2007, 2, 131-137.

48. Panchawat, S. and Sisodia, S. S., In vitro antioxidant activity of Saraca asoca Roxb. de Wilde stem bark extracts from various extraction processes. Asian J. Pharm. Clin. Res., 2010, 3, 231-233.

49. Pandey, A. K., Ojha, V., Yadav, S. and Sahu, S. K., Phytochemical evaluation and radical scavenging activity of Bauhinia variegata, Saraca asoca and Terminalia arjuna barks. Res. J. Phytochem., 2011, 5, 89-97.

50. Sadhu, S. K., Khatun, A., Phattanawasin, P., Ohtsuki, T. and Ishibashi, M., Lignan glycosides and flavonoids from Saracaasoca with antioxidant activity. J. Nat. Med., 2007, 61, 480482.

51. Pal, T. K., Bhattacharyya, S. and Dey, A., Evaluation of antioxidant activities of flower extract (fresh and dried) of Saraca indica grown in West Bengal. Int. J. Curr. Microbiol. Appl. Sci., 2014, 3, 251-259.

52. Mir, M. A., Sawhney, S. S. and Kumar, S., Comparative study upon the antioxidant potential of Saraca indica and Pterospermum acerifolium. J. Chem. Pharm. Res., 2012, 4, 4716-4720.

53. Prathapan, A., Nampoothiri, S. V., Mini, S. and Raghu, K. G., Antioxidant, antiglycation and inhibitory potential of Saraca asoca flowers against the enzymes linked to type 2 diabetes and LDL oxidation. Eur. Rev. Med. Pharmacol. Sci., 2012, 16, 57-65.

54. Katiyar, S., Patidar, D., Gupta, S., Singh, R. K. and Singh, P., Some Indian traditional medicinal plants with antioxidant activity: a review. Int. J. Innovat. Res. Sci. Eng. Technol., 2013, 2, 7303-7314.

55. Kumar, S., Narwal, S., Kumar, D., Singh, G., Narwal, S. and Arya, R., Evaluation of antihyperglycemic and antioxidant activities of Saraca asoca (Roxb.) De Wild leaves in streptozotocin induced diabetic mice. Asian Pac. J. Trop. Med., 2012, 1, 170 176.

56. Verma, A., Jana, G. K., Chakraborty, R., Sen, S., Sachan, S. and Mishra, A., Analgesic activity of various leaf extracts of Saraca indica Linn. Der Pharm. Let., 2010, 2, 352-357.

57. Kapoor, L. D., Handbook of Ayurvedic Medicinal Plants, 2001, 1 st edn, p. 298.
58. Nag, D., Ghosh, M. and Mukherjee, A., Antimutagenic and genoprotective effects of Saraca asoca bark extract. Toxicol. Indian Health, 2013, 8, 696-703.

59. Mukherjee, T., Chowdhury, S., Kumar, A., Majumder, H. K., Jaisankar, P. and Mukhopadhyay, S., Saracoside: a new lignan glycoside from Saraca indica, a potential inhibitor of DNA topoisomerase IB. Nat. Prod. Commun., 2012, 7, 767-769.

60. Mukhopadhyay, M. K. and Nath, D., Phytochemical screening and toxicity study of Saraca asoca Bark. Int. J. Phytomedi., 2011, 3, 498-505.

61. Shirolkar, A., Gahlaut, A., Chhillar, A. K. and Dabur, R., Quantitative analysis of catechins in Saracaasoca and correlation with antimicrobial activity. J. Pharm. Anal., 2013, 3, 421-428.

62. Begum, S. N., Ravikumar, K. and Ved, D. K., 'Asoka' - an important medicinal plant, its market scenario and conservation measures in India. Curr. Sci., 2014, 107, 26-28.

63. Mitra, S. K., Gopumadhavan, S., Venkataranganna, M. V., Sarma, D. N. K. and Anturlikar, S. D., Uterine tonic activity of U-3107 (EveCare), a herbal preparation in rats. Indian J. Pharm., 1999, 31, 200-203.

64. Satyavati, G. V., Prasad, D. N., Sen, S. P. and Das, P. K., Oxytocic activity of a pure phenolic glycoside (P2) from Saraca indica Linn (Ashoka): a short communication. Indian J. Med. Res., 1970, 58, 660-663.

65. Dabur, R., Gupta, A., Mandal, T. K., Singh, D. D., Bajpai, V., Gurav, A. M. and Lavekar, G. S., Antimicrobial activity of some Indian medicinal plants. Afr. J. Trad. CAM, 2007, 4, 313-318.

66. Kaur, J. D. and Misra, K., Biological and pharmacological activity of Saraca asoca: anticancer activity. J. Indian Chem. Soc., 1980, 57(12), 1243.

67. Yadav, N. K. et al., Saraca indica bark extract shows in vitro antioxidant, antibreast cancer activity and does not exhibit toxicological effects. Oxid. Med. Cell. Longev., 2015, doi: 10.1155/ $2015 / 205360$

68. Ghosh, S., Majumder, M., Majumder, S., Ganguly, N. K. and Chatterjee, B. P., Saracin: a lectin from Saraca indica seed integument induces apoptosis in human T-lymphocytes. Arch. Biochem. Biophys., 1999, 371, 163-168.

69. Shelar, D. B., Shirote, P. J. and Naikwade, N. S., Antiinflammatory activity and brine shrimps lethality test of Saraca indica (Linn.) leaves extract. J. Pharm. Res., 2010, 3, 2004-2006.

70. Swamy, A. H. M. V., Patel, U. M., Koti, B. C., Gadad, P. C., Patel, N. L. and Thippeswamy, A. H. M., Cardioprotective effect of Saraca indica against cyclophosphamide induced cardiotoxicity in rats: a biochemical, electrocardiographic and histopathological study. Indian J. Pharmacol., 2013, 45, 44-48.

71. Maruthappan, V. and Sakthi Shree, K.,. Antiulcer activity of aqueous suspension of Saraca indica flower against gastric ulcers in albino rats. J. Pharm. Res., 2010, 3(1), 17.

72. Gahlaut, A., Shirolkar, A., Hooda, V. and Dabur, R., $\beta$-sitosterol in different parts of Saraca asoca and herbal drug ashokarista: quali-quantitative analysis by liquid chromatography-mass spectrometry. J. Adv. Pharm. Technol. Res., 2013, 4, 146-150.

73. Khatoon, S., Singh, N., Kumar, S., Srivastava, N., Rathi, A. and Mehrotra, S., Authentication and quality evaluation of an important Ayurvedic drug - Ashoka bark. J. Sci. Ind. Res., 2009, 68, 393-400.

74. Godara, D., Kaushik, V., Sharma, G. and Saini, V., A method of isolation of Capparisterol from Capparis decidua and antinephrolithiasis activity. Am. J. Adv. Drug. Del., 2015, 3, 86-94.

75. Verma, A., Jana, G. K., Sen, S., Chakraborty, R., Sachan, S. and Mishra, A., Pharmacological evaluation of Saraca indica leaves for central nervous system depressant activity in mice. J. Pharm. Sci. Res., 2010, 2(6), 338-343.

76. Yadav, G., Garg, V. K., Thakur, N. and Khare, P., Locomotor Activity of methanolic extract of Saraca indica bark. Adv. Biol. Res., 2013, 7, 1-3. 
77. Sarojini, N., Manjari, S. A. and Kanti, C. C., Phytochemical screening and anti-helminthic activity study of Saraca indica leaves extract. Int. Res. J. Pharm., 2011, 2, 194-197.

78. Nadakarni, K. M., The Indian Materia Medica, Popular Book Depot, Bombay, 1957, 3rd edn, p. 1075.

79. Varaprasad, N. et al., Antipyretic activity of methanolic extract of Saraca asoca (roxb.) de Wild leaves. Int. J. Pharm. Res. Dev., 2011, 3, 202-207.

80. Sasmal, S., Majumdar, S., Gupta, M., Mukherjee, A. and Mukherjee, P. K., Pharmacognostical, phytochemical and pharmacological evaluation for the antipyretic effect of the seeds of Saraca asoca Roxb. Asian Pac. J. Trop. Biomed., 2012, 2, 782-786.

81. Kalakotla, S., Mohan, G. K., Rani, M. S., Divya, L. and Pravallika, P. L., Screening of Saraca indica (Linn.) medicinal plant for antidiabetic and antioxidant activity. Der. Pharm. Lett., 2014, 6, 227-233.

82. Ahmad, F., Misra, L., Tewari, R., Gupta, P., Mishra, P. and Shukla, R., Anti-inflammatory flavonol glycosides from Saraca asoca bark. Nat. Prod. Res., 2015, 23, 1-4.

83. Somani, G. and Sathaye, S., Bioactive fraction of Saraca indica prevents diabetes induced cataractogenesis: an aldose reductase inhibitory activity. Pharmacogn. Mag., 2015, 11, 102-110.

84. Gupta, M., Sasmal, S. and Mukherjee, A., Therapeutic effects of acetone extract of Saraca asoca seeds on rats with adjuvantinduced arthritis via attenuating inflammatory responses. ISRN Rheumatol., 2014, 2004, pp. 1-12.

85. Pradhan, P., Joseph, L., George, M., Kaushik, N. and Chulet, R., Pharmacognostic, phytochemical and quantitative investigation of Saraca asoca leaves. J. Pharm. Res., 2010, 3, 776-780.

86. Sarojini, N., Manjari, S. A. and Kanti, C. C., Phytochemical screening and antibacterial activity study of Saracaindica leaves extract. Int. Res. J. Pharm., 2011, 2, 176-179.

87. Mittal, A., Kadyan, P., Gahlaut, A. and Dabur, R., Nontargeted identification of the phenolic and other compounds of Saraca asoca by high performance liquid chromatography-positive electrospray ionization and quadrupole time-of-flight mass spectrometry. ISRN Pharm., 2013, 1-10.

88. Rodriguez, R. J., White, Jr. J. F., Arnold, A. E. and Redman, R. S., Fungal endophytes: diversity and functional roles. New Phytol., 2009, 182, 314-330.

89. Jansen, R. and Murali, T. S., Fungal endophytes and bioprospecting. Fungal Biol. Rev., 2009, 23, 9-19.

90. Kuriakose, G. C., Singh, S., Rajvanshi, P. K., Surin, W. R. and Jayabaskaran, C., In Vitro cytotoxicity and apoptosis induction in human cancer cells by culture extract of an endophytic Fusarium solani strain isolated from Datura metel L. Pharm. Anal. Acta, 2014, 5, 1-8

91. Strobel, G., Daisy, B. and Castillo, U., The biological promise of microbial endophytes and natural products. Plant Pathol. J., 2005, 4, 161-176.

92. Aly, A. H., Abdessamad, D., Julia, K. and Peter, P., Fungal endophytes from higher plants: a prolific source of phytochemicals and other bioactive natural products. Fungal Divers., 2010, 41, $1-16$.

93. Suryanarayanan, T. S., Thirunavukkarasu, N., Govindarajulu, M. B., Sasse, F., Jansen, R. and Murali, T. S., Fungal endophytes and bioprospecting: an appeal for a concerted effort. Fungal Biol. Rev., 2009, 23, 1-19.
94. Jain, P., Aggarwal, V., Sharma, A. and Pundir, R. K., Isolation, production and partial purification of protease from an endophytic Acremonium sp. J. Agric. Tech., 2012, 8, 1979-1989.

95. Jain, P., Aggarwal, V., Sharma, A. and Pundir, R. K., Screening of endophytic fungus Acremonium sp. for amylase production. J. Agric. Tech., 2012, 8, 1353-1364.

96. Jinu, M. V., Gini, C. K. and Jayabaskaran, C., In vitro antioxidant activity of cholestanol glucoside from an endophytic fungus Lasiodiplodia theobromae isolated from Saraca asoca. J. Chem. Pharm. Res., 2015, 7, 952-962.

97. Jinu, M. V., Gini, C. K. and Jayabaskaran, C., Modulating the biosynthesis of a bioactive steroidal saponin, cholestanol glucoside by Lasiodiplodia theobromae using abiotic stress factors. Int. J. Pharm. Pharm. Sci., 2015, 7(7), 114-117.

98. Jinu, M. V. and Jayabaskaran, C., Media optimization for the production of a bioactive steroidal saponin, cholestanol glucoside by Lasiodiplodia theobromae. Eur. J. Exp. Biol., 2015, 5(4), 2836.

99. Jinu, M. V. and Jayabaskaran, C., Diversity and anticancer activity of endophytic fungi associated with the medicinal plant Saraca asoca. Curr. Res. Env. Appl. Mycol., 5(3), 169-179.

100. Kusari, S., Singh, S. and Jayabaskaran, C., Biotechnological potential of plant-associated endophytic fungi: hope versus hype. Trends Biotechnol., 2014, 32, 297-303.

101. Beena, C. and Radhakrishnan, V. V., Quality assessment evaluation of the market samples of important ayurvedic drug asoka bark. Ann. Phytomed., 2012, 1(1), 95-98.

102. Mathew, S., Mathew, G., Joy, P. P., Skaria, B. P. and Joseph, T. S., Differentiation of Saracaasoca crude drug from its adulterant. Ancient Sci. Life, 2005, XXIV(4), 174-178.

103. Pavarini, D. P., Pavarini, S. P., Niehues, M. and Lopes, N. P., Exogenous influences on plant secondary metabolite levels. Anim. Feed Sci. Technol., 2012, 176(1-4), 5-16.

104. Ramakrishna, A. and Ravishankar, G. A., Influence of abiotic stress signals on secondary metabolites in plants. Plant Signal Behav., 2011, 6(11), 1720-1731.

105. Achakzai, A. K. K., Palwasha, A., Masood, A., Kayani, S. A. and Tareen, R. B., Response of plant parts and age on the distribution of secondary metabolites on plants found in Quetta. Pak. J. Bot., 2009, 41(5), 2129-2135.

106. Saha, J., Gupta, K. and Gupta, B., Phylogenetic analyses and evolutionary relationships of Saraca asoca with their allied taxa (Tribe-Detarieae) based on the chloroplast matK gene. J. Plant Biochem. Biotechnol., 2013, doi: 10.1007/s13562-013-0237-3.

107. Sumangala, R. C., Shaanker, R. U., Dayanandan, S., Vasudeva, R. and Ravikanth, G., Identification of novel microsatellite markers for Saraca asoca, a medicinally important tree species in India. J. Genet., 2013, 92, 93-95.

108. Dev, S., Prime Ayurvedic Plant Drugs, 2012, 2nd edn, p. 464.

109. Behari, M., Andhiwal, C. K. and Streibl, M., Hydrocarbons, esters and free alcohols in the bark of Saraca indica L. Collect. Czech. Chem. Commun., 1977, 42, 1385-1388.

Received 25 October 2014; revised accepted 30 July 2015

doi: $10.18520 / \mathrm{v} 109 / \mathrm{i} 10 / 1790-1801$ 